\title{
Methods for co-creating with older adults in living laboratories: a scoping review
}

\author{
Pamela Knight-Davidson $^{1}$ (D) Pauline Lane ${ }^{1} \cdot$ Andrew McVicar $^{2}$
}

Received: 2 January 2020 / Accepted: 14 May 2020 / Published online: 15 June 2020

(C) The Author(s) 2020

\begin{abstract}
The purpose of this literature review is to enhance understanding of methods and processes used in living laboratories, (henceforth living labs), that are concerned with the co-creation of technological and service innovations with older adults. It is relevant to the growing discourse about how to enable the uptake and use of goods and services designed to promote older adults' independence and how to amplify the potential for economic growth that the demand for such goods and services offers. In this paper, the methods for co-creating with older adults in living labs are explored through a scoping review of the literature. The review utilises a set of tools advanced by Arksey and O'Malley's (Int J Soc Res Methodol 8(1):19-32, 2005) framework, to collect, evaluate and present the available literature and provide a rigorous and transparent analysis to allow other researchers to replicate the study if they so wish. The findings suggest that a broad range of methods (some of which follow user-centred design and participatory research approaches) are used in living laboratories with older people from being observed interacting with products to them having full involvement in design processes and activities. These might be carried out over short, mid or long durations and in a variety of temporary or permanent settings (e.g., personal homes, mock-up homes, community centres). The analysis also points to greater value being placed on those methods that have high and active user involvement in co-creation, in comparison to methods that have lower engagement with users in the process. However, reflecting on the literature, the authors of this paper suggest that when co-creating with older adults, a level of creative thinking might be necessary, particularly in situations where user needs cannot be readily articulated and this may indicate the need for using less active user involvement methods. This review of the literature suggests that inclusive, user-centred approaches are most conducive with 'needs finding' and effective 'co-creation' with older adults. Moreover, individual living labs can benefit from adopting a repertoire of methods, borrow from other disciplines, and adapt a flexibility of approach for effective co-creation with older adults.
\end{abstract}

Keywords Living lab $\cdot$ Co-creation $\cdot$ Oder adults $\cdot$ Silver economy $\cdot$ Innovation $\cdot$ Technology $\cdot$ User-involvement

\section{Introduction}

Concerns about population ageing across Europe have traditionally been debated in relation to the economic burden it presents to society. However, in recent years, there has been focus on the potential of the "Silver Economy" that is emerging in response to the demand for age-related products and

Pamela Knight-Davidson

pamela.knight-davidson@anglia.ac.uk

1 Positive Ageing Research Institute, Faculty of Health, Education, Medicine and Social Care, Anglia Ruskin University, Bishop Hall Lane, Chelmsford, UK

2 Faculty of Health, Education, Medicine and Social Care, Anglia Ruskin University, Bishop Hall Lane, Chelmsford, UK services which are opening up new opportunities and markets [14]. Universities, public sector organisations and private entrepreneurs are rising to the challenge of developing and introducing innovative solutions, including technological solutions, that aim not only to enable older adults to remain independent for longer, but which also have the potential to reduce welfare costs. Moreover, many of these solutions are being bolstered by national investments. For example, the government in the United Kingdom has proposed an ambitious Healthy Ageing Challenge Fund, incentivising the science and technology communities to collaborate with appropriate agencies to produce solutions that might increase the health span and years of independence of older adults, by five years (Industrial Strategy: Building a Britain fit for the Future [17]). For instance, the ability of older adults to live independently in their own homes can potentially be aided by the emergence of 
a number of information and communication technologies, and assistive technologies which theoretically have the potential to reduce health [and social] care costs [18].

However, despite the optimism about the Silver Economy, a counter discourse has been emerging about the uptake and use of products and services by and for older adults (e.g., [27]) and about formulas that work to ensure the most promising products enter the market. In particular, there has been much debate about widespread adoption of Assistive Living Technologies, (ALTs) which support daily living in the home. Several authors have suggested that the 'adoption' of new technologies by older adults remains a goal rather than a reality $[16,18,30]$ while other authors have suggested that innovating with and for older adults presents a number of barriers [13] including social; emotional (e.g., [24]) and regulatory factors in social care provision that may also impact on the development and uptake and use of new technologies and services.

Moreover, within this counter discourse, there is also an undercurrent of ageist and damaging assumptions about older adults that have influenced, and continue to influence, the development of products. For example, there is association of ageing with decline and frailty, which encourages a narrow focus on products to treat or manage declining health [10] and misrepresents a large proportion of older adults. These are largely overlooked, but might, in fact, deter older adults from adopting many of the solutions being developed.

These debates highlight the need for stakeholders (i.e., businesses, inventors, entrepreneurs, researchers, governments, health and social care providers) to understand the multiplicity of factors that might enable acceptance of solutions by older adults, which go beyond factors identified in, for example, the Unified Theory of Acceptance and Use of Technology [32], which is more suited to identifying factors influencing the use of already developed products. It is desirable for innovators, in particular, to understand older adults' viewpoints in relation to innovation so that they might develop products and services that older adults want, prefer or need, in order to support maximal uptake. Living labs are often advocated as a positive approach to research and product development that might aid such understanding.

\subsection{Living labs and co-creation}

It is notable that living labs are receiving attention and high regard among developers in the Silver Economy market, particularly in relation to the concept of 'co-creation' that they promote. However, the concept of living labs is relatively under-articulated among the relevant stakeholders who might benefit from engaging with them but to date, there has only been very limited systematic analyses (e.g., [15]), identifying [and documenting] the range of activities used in living labs [6], and how they relate to the target user group [4]. It is indicated that supporting theories to help understanding of the concept are limited (e.g., [6]), although from the various definitions, typologies, characterisations, and conceptualisations found in the literature (e.g., [29, 35]- European Network of Living Labs, 2015 definition; [20, 21]), some information might be elicited (see Table 1 for more detail).

A useful depiction in the wider literature (outside the papers of this review) relevant to the focus on methods in this current review suggests that living labs can be conceived as

Table 1 Concepts, characterisations and definitions of living labs

\begin{tabular}{|c|c|c|}
\hline Author & $\begin{array}{l}\text { Definition/ } \\
\text { Categorisation }\end{array}$ & Definition \\
\hline $\begin{array}{c}\text { European Network } \\
\text { of Living Labs- } \\
\text { ENoLL, (2015) }\end{array}$ & $\begin{array}{l}\text { Living lab } \\
\text { definition }\end{array}$ & $\begin{array}{l}\text { "Living Labs are defined as } \\
\text { user-centred, open } \\
\text { innovation ecosystems } \\
\text { based on a systematic user } \\
\text { co-creation 1 approach } \\
\text { integrating research and } \\
\text { innovation processes in } \\
\text { real life communities and } \\
\text { settings. In practice, Living } \\
\text { Labs place the citizen at } \\
\text { the centre of innovation, } \\
\text { and have thus shown the } \\
\text { ability to better mould the } \\
\text { opportunities offered by } \\
\text { new ICT concepts and } \\
\text { solutions to the specific } \\
\text { needs and aspirations of } \\
\text { local contexts, cultures, } \\
\text { and creativity potentials" }\end{array}$ \\
\hline $\begin{array}{l}\text { Schuurman et al. } \\
\text { [29] }\end{array}$ & $\begin{array}{l}\text { Living lab } \\
\text { typologies }\end{array}$ & $\begin{array}{l}\text { Schuurman proposed four } \\
\text { general living lab types: } \\
\text { (1) American living labs } \\
\text { (2) testbed-like living labs } \\
\text { (3) living labs focused on } \\
\text { intense user co-creation } \\
\text { (4) living labs mainly as } \\
\text { facilitators for } \\
\text { multi-stakeholder collabo- } \\
\text { ration and knowledge } \\
\text { sharing }\end{array}$ \\
\hline Lander [20] & $\begin{array}{l}\text { User involvement } \\
\text { from a Design } \\
\text { perspective }\end{array}$ & $\begin{array}{l}\text { 1. User-centred design - users } \\
\text { involved at testing stage: } \\
\text { design for users) } \\
\text { 2.Participatory design -users } \\
\text { can be involved at both } \\
\text { design and testing stage: } \\
\text { design with users } \\
\text { 3. Full-involvement - users } \\
\text { involved at all stages: de- } \\
\text { sign by users. }\end{array}$ \\
\hline Leminen et al. [21] & $\begin{array}{l}\text { User involvement } \\
\text { relationships }\end{array}$ & $\begin{array}{l}\text { Informant, } \\
\text { Contributor } \\
\text { Collaborator }\end{array}$ \\
\hline
\end{tabular}


[innovation ecosystems], spaces where designers and researchers find inspiration by observing users" as well as an innovation approach "where [innovators] may test hypotheses through experimentation" ([13] p. 63, [6]). Here it should be noted that characterisations of living labs as intermediary organisations is outside the scope of this paper. The idea of living labs as an innovation approach is relevant and is important to the current review as this perspective implies the use of set, or particular methodologies, which might be documented. We might also gain insight from the methods of other innovation approaches that are said to have similarities with living labs, for example Chesbrough's, [11] 'open innovation approach' where companies open their processes and boundaries to other stakeholders with a view to inspiring creativity [6], and design approaches that advocate incorporation of user perspectives and user involvement (e.g., user-centred approaches such as "participatory design" and "socio-technical design", [5]).

These more contemporary conceptualisations of living labs evoke tangible participation of end-users in design processes and a move away from processes that treated users as subjects and targets for experiments' ([35] p128, [28]). Rather, it is implied that people ought to be regarded as partners that create a service together ([35] p128, [24, 28]) with developers, or indeed that they should be empowered to develop products themselves [19]. This appears to be the central message of 'co-creation'. However, the array of descriptions of living labs and of co-creation may make it difficult for researchers/developers starting out in this field to identify, adopt and apply the methods [35] nor the roles of older adults in their own co-creation or living lab processes. Practical application of living lab methods is therefore hampered by terminologies that are not well defined. This paper therefore seeks to enhance understanding of the range of methods and processes used in living labs that have a focus on older adults by examining what they entail in practice.

\subsection{Aims and objectives}

This paper aims to provide an overview of methods that are used/have been used in co-creation with older people to enhance understanding and inspire future research.

The objectives are to,

1. Scope the existing literature on living laboratories concerned with older people, and

2. Identify and document the applied methods used by researchers for co-creation.

\section{Search and selection}

For this paper, the authors utilised the Arksey and O'Malley's [3] methodological framework for conducting scoping studies. This approach aims to 'examine the extent, range, and nature of research activity, to determine the value for undertaking a full systematic review, to summarize and disseminate research findings, and to identify research gaps in the existing literature' (Arksey and O'Malley [3], p21).

Databases CINAHL, Medline, PubMed and Scopus were searched to identify papers that utilised living lab methods or have reported on methods in living labs with a focus on independent living. The following search terms, Boolean operators and filters were used: "Living labs" AND "older adults" OR "seniors" OR "elders" AND "co-creation" OR "co-design". The searches were limited to the years 2008-2018, to the academic literature, and to the English language. Notably, rather than 'being guided by a highly focussed research question, that lends itself to searching for particular study designs' at this stage, according to the framework of Arksey and O'Malley, ([3] p4), the search was guided by a requirement to identify all relevant literature relating to co-creating with older adults, regardless of study design.

The results of this initial search of the databases generated 119 articles. Further, a follow-up Google Scholar search was carried out using the same search terms and generated 7790 results. As a next step, following the iterative methods suggested by Arksey and O'Malley [3], where the previous search had not included the word "methods", it was considered necessary to include this word in the search, particularly as identified papers in the previous step had generated articles that did not report on methods of co-creation. The search was made more specific in the listed databases (CINAHL, Medline, PubMed and Scopus) and in Google Scholar. The search terms "Co-creation" AND methods AND "living labs" AND "older adults" OR "seniors" OR "elders" were applied. No further papers were identified from this subsequent search of the databases. The new Google Scholar search yielded 679 results, making a total of 798 papers (119 from the database searches and 679 from the second google scholar search) for consideration. The abstracts of these were examined by PK-D, AM and PL and the following exclusions applied: papers that did not report on methods of co-creation and papers concerned with smart cities (the latter made up a significant number of the articles generated in the google scholar search). Papers that did not feature older people in co-creation processes, that is, they did not refer to people age $65+$ and/ or did not associate their study cohort with the words 'older', 'elder' or 'senior' in the title, abstract, or in the introductions of the papers, were also excluded.

This process left thirty-four papers that were reviewed in their entirety. Twenty of these were excluded, either because 
they didn't report on methods used/ proposed methods for use, in a living lab or related to a consortium of living labs. Fourteen articles were included in the review. In addition to describing the results in Table 2, and in order to allow scrutiny of potential cultural and/or organisational influencers

\subsection{The living labs}

Focusing on the idea of living labs as an innovation approach, overall, the described methods in the reviewed papers reveal a real appetite to find solutions to the challenges posed by pop-

\section{Flow diagram of search and selection process}

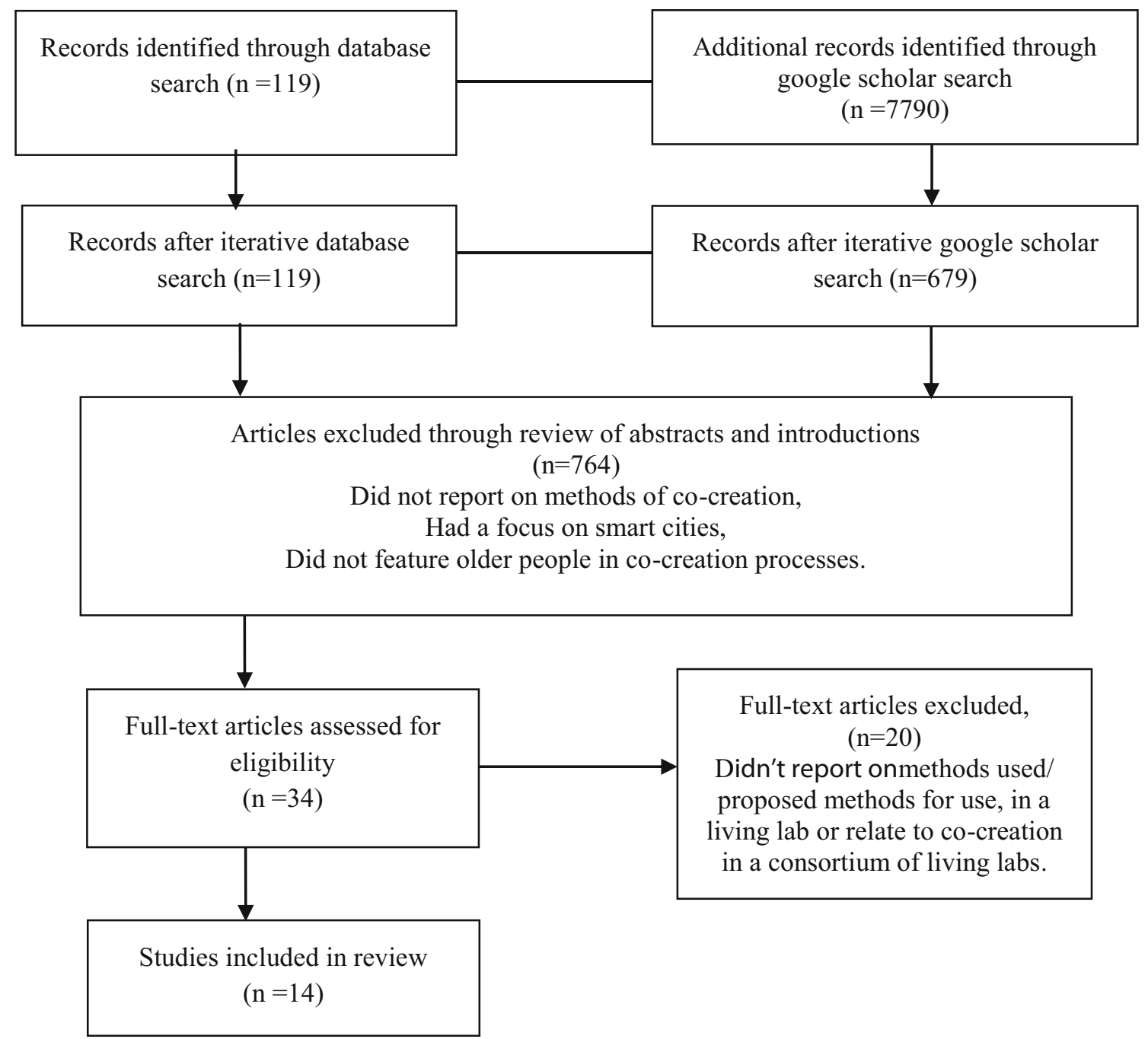

related to particular methods, sections $3.3,3.3$ and 3.4 also provides details of the geographical regions of the living labs, the purposes/motivations for the living labs, and the actors concerned in the development and activities in the living labs.

\section{Results}

From this point onwards, the papers will be referred to by the study author(s), as identified in Table 2. ulation ageing and relate to a range of solutions, including, for the development of technological products, service implementation, and even processes to build and sustain communities (see section 3.5). An array of methods are described in Table 2 ranging from university desk research to immersive ethnographic methods. They cover a broad range of mixed and disparate descriptions of processes and the roles that users play or might play in enabling co-creation. It is evident that a number of the papers propose methods adopted, for example, user-centred Design approaches (e.g., storyboarding techniques [24] and community based participatory research [2]. 
Table 2 Described methods and methodological drivers in the selected papers

Author(s), Year Country $\quad \begin{aligned} & \text { Purpose/motivations of the living lab } \\ & \text { methods }\end{aligned} \quad$ Methods Described/Proposed methods

\section{Angelini et al., (2016), Senior Living Lab: Switzerland An Ecological Approach to Foster Social Innovation in an Ageing Society.}

van Geenhuizen, (2014), Living Labs, Concepts and Critical Factors, with Case Studies in Health Care.

Netherlands .

(1)

Brankaert and den Ouden, (2017), The
Design- Driven Living Lab: A New
Approach to Exploring Solutions to
Complex Societal Problems.
Pedell et al., (2016), Methods for Australia Supporting Older Users in Communicating Their Emotions at Different Phases of a Living Lab Project.
Wang and Xing, (2014), Design Intelligent China Service for Elderly People Using Living Lab Approach.

Netherlands
Co-creation of innovation promoting ageing well at home

Case 1

Provision of affordable ICT for home care and home fitness training, specifically adapted for Turkish community.

Case2

Provision of sensor technology (to Turkish community) to measure activities of daily living, need for support and to make combinations with other products and services, such as alarm systems.

Evaluation of a design driven living lab approach to the implementation of Qwiek.up system.

Identification of latent uses of the system, discover new perspective on the value proposition of the system

Understand user emotions in the development of a prototype pendant alarm.

Proposal of a living lab methodology for service design mediated through ICT (To address scarcity of medical resources).

Pino et al., (2013), Contribution of the Living Lab Approach to the Development, Assessment, and Provision of Assistive Technologies, for Supporting Older People with Cognitive Disorders.
France

Focus on assistive technologies for supporting older adult with cognitive disorders.

Understand needs of older people living with cognitive impairment.

Empowerment of older people to be involved in product development. Proposal of Spiral Method
'Ethnological approaches'

Community Based Participatory Research methods

Focus groups

World café

Shadowing techniques

Community 'needs analysis' prior to the project.

Use of in-group coach/trainer to gain trust.

Interviews with users about testing the ICT applications.

Designing scenarios on future use with users.

Users acting in focus groups.

'Co-creation' of specific applications'.

Life test (put the product in a care facility and let care professionals use it as they will).

After-use description of experiences on evaluation forms (professionals).

Focus groups (professionals).

Proposal of an Emotion-led Design Toolkit across the three generic design phases (interviews, creation of animated scenarios, co-design workshop discussions, use of technology probes).

ICT mediated information gathering (e.g., wireless camera, smartphone for the elderly, online interviews).

ICT data collection methods e.g., VR, 3D imitation, imitation video, feedback of data via ICT.

Use of big database technology and big data processing methods.

(Iterative design process and continuous gathering of user feedback).

Direct observations.

Surveys/Questionnaires.

Assistive Technology Assessment

procedures (user-driven process to seek and evaluate assistive technologies).

Interviews.

Idea generation as plays (researchers act out the use of a given solution in format of the users and monitor verbal or non-verbal reactions).

Organize testing sessions as recreational activities and gather feedback.

(4-step participatory approach),

1.Lowering technology barrier

Traditional computer courses and workshops, introductory courses

2. Direct involvement with tech

Learning by doing using mobile devices and applications.

3. Intergenerational involvement with developers 
Table 2 (continued)

Author(s), Year Country $\quad \begin{aligned} & \text { Purpose/motivations of the living lab } \\ & \text { methods }\end{aligned} \quad$ Methods Described/Proposed methods
methods

\author{
Andersen, Kanstrup and Yndigegn, (2018), Denmark, \\ Three Living Labs in Denmark: \\ Challenges with Co-design and \\ Portugal, \\ and Austria
} Implementation of Heath IT
Case 1

Give and Take project information technology (reciprocal sharing of services and resources among older adults)

\section{Case2}

Evaluation of implementation of various assistive living technologies for elderly, chronically ill and handicapped in nursing homes

France

Pino et al., (2015), Innovative

Technology-Based Healthcare and Support Services for Older adults: How and Why Industrial Initiatives Convert to the Living Lab Approach simulation of a whole design process, a design competition between teams (older people and young designers in direct co-operation) teamwork

4. Participant Empowerment

Co-design contest (between older people co-operating with young designers)

Dialogue Meetings and workshops to explore the concept of sharing, with older adults, municipalities and private partners.

Setting up of a living lab (as a space for rehearsing the co-ordination practices).

Dialogue meetings and workshops,

Observations of formed communities,

"small experiments" for exploration of technologies.

Observation of use of installed technologies.

Individual interviews and observations with staff, managers, municipality and residents.

Co-design workshop (in one nursing home)

Phase 1: needs assessment through questionnaires and debriefing focus group. $(\mathrm{n}=17)$

Phase 2a: Task analysis and definition of system requirements based on phase 1results and analysis of existing services

$2 b$ : Interviews with older adults to inform production of a booklet with fictional use scenarios for recruitment for the pilot assessment $(\mathrm{n}=10)$

Phase 3: Specification of an ergonomics/usability of the system and interface design.

Phase 4: Iterative usability using a mock-up prototype and prototype refinement $\mathrm{n}=14$.

Phase 5: Pilot with MPV in real-life settings $(\mathrm{n}=300)$

(Following negative feedback-new livinglab method proposed):

Participants actively involved in the writing of use-scenarios to identify unmet needs

System include in a storyboard-participants asked to imagine potential problems when using the system.

Formulate alternatives to the political/economic driven agenda for senior citizens.

To design new horizontal service concepts to strengthen social interaction among seniors,

contributing to greater self-reliance and social wellbeing.
A series of design labs (3 workshops)

Phase 1:

Individual visits prior to the $1^{\text {st }}$ workshop by project group.

Development of personal workbook with individual stories and life fragments for each participant.

Formulation of 11 themes relevant to seniors' everyday lives.

Use of props to explore one a 'good to share' experience. 
Table 2 (continued)

Author(s), Year Country $\quad \begin{aligned} & \text { Purpose/motivations of the living lab } \\ & \text { methods }\end{aligned} \quad$ Methods Described/Proposed methods
methods

Brankaert and den Ouden, (2013), Setting Netherlands up a living lab for innovation in the dementia care chain, a case study of the PhysiCAL

\section{Vermueulen et al., (2015), eLabel: Technology-Supported Living Labs in Primary Care.}

Netherlands
Implementation of ehealth and telecare technologies in primary care to support transition from traditional care to telecare and e-health

Development process to design innovative products and related services for people living with dementia.

(Physical- activity reminder calendar- as an example)

pain, Italy

Greece, UK

Finland,

France, and

Cyprus.
Proposed method for the validation of services for the assisted living of older people T-seniority project.

\section{of Services for
Elderly People}

Seniors played out what a good shared experience would look like in their livesplayed out stories used to design services

by private service provides and municipalities.

Phase 2:

A number of innovative concepts sketched on a technological platform.

Phase3:

Proposal to use seniors' homes as design experimental platforms.

After use feedback (Older people and carer jointly interviewed)

Care chain consultations in 3 workshops

(Evaluation of the product and evaluation of the living lab approach).

Discussion of companies' main drivers in a workshop, (evaluation of the product and the living lab concept).

1st phase: All stakeholders collaborate to select telecare technologies and eHealth applications.

2nd phase: Implementation of technologies into primary care.

Two-year follow up study to assess the impact on patient experiences professionals and organisations.

$3^{\text {rd }}$ phase: Development of implementation strategies based on findings of longitudinal study and experiences of patients and professionals.

Assessment of services proposed with real users in long-term test beds (home settings).

Direct analysis, using remote data collection techniques and strategies (like technological monitoring) and software logging tools on devices like mobile phones or smart TVs and on network (online) platforms.

Indirect analysis, focus groups, in-depth interviews and self-reporting techniques (e.g. diaries).

'Following user journeys across a sea of devices and services'.

Feedback,

(post measurement using same techniques as in previous steps and a set of technological recommendations).

Categorisation of living labs into 2 types:

Hypothesis search:

End-users are partners in early design phases (i.e., problem identification). End -user activities include, planning, designing, and creating with developers; active involvement in problem identification, concept development, and testing in real life settings, and small social experiments using prototypes. Hypothesis verification: 
Table 2 (continued)

\begin{tabular}{|c|c|c|c|}
\hline Author(s), Year & Country & $\begin{array}{l}\text { Purpose/motivations of the living lab } \\
\text { methods }\end{array}$ & Methods Described/Proposed methods \\
\hline & & & $\begin{array}{l}\text { Older people test products provided by } \\
\text { companies, verify the usability of } \\
\text { services and tools, and give advice for } \\
\text { improvement to companies. } \\
\text { Collaboration between companies, older } \\
\text { people and municipalities to create ideas } \\
\text { as well as verify and improve new } \\
\text { products and services that the healthcare } \\
\text { industry provides. }\end{array}$ \\
\hline
\end{tabular}

This affirms that living lab methods are closely related to other user-centred approaches. In some cases (e.g., [31]) the methods are not made transparent by the authors e.g., the term 'co-creation' of specific applications is used, but as discussed earlier (see 1.1) the notion of 'co-creation' is that of partnership working, thus use of the term in this example leaves the reader guessing about the exact nature of the unspecified involvement of the end-users in developing/designing ICT solutions. Likewise, the specific activities for conducting a 'needs analysis' in this example, are not made clear, although notably the aims of this paper were to discuss critical factors in developing living labs and so a focus on the methods may not have been a central concern of the authors.

\subsubsection{Duration of living lab processes}

An important observation that emerges from the analysis relates to the length of time that activities might be run for. Andersen et al. [1] describe implementation of welfare technologies in nursing homes as a living lab activity over 3 months whilst Vermueulen et al. [33] describe activities lasting over more than 2 years. Likewise, the activities proposed by Moutmtzi and Wills [23], clearly involve elaborate living lab processes to gather feedback of real-life use of integrated care e-Services mediated throughout television and these are proposed to occur over a long period of time. Other activities described in the selected papers might be momentary in comparison (e.g., one-off focus group sessions). Thus, living lab activities might be implemented in the short, mid or long term and might be multifaceted or involve a single activity.

\subsubsection{Older peoples' involvement}

With regard to older people's involvement in living lab processes specifically, a finding of mixed degrees of user involvement is consistent with previous observations that there is not a unique definition of how older adults should be involved in co-creation, (e.g., [2]). The current review of older adults' involvement in co-creation processes varies across the fourteen papers reviewed, from being observed interacting with already developed products in lab type settings (e.g., [9, 25]) to working alongside designers in the complete design processes of a product or service, or from concept development to marketing and/or use implementation (e.g. [19]).

\subsubsection{Location of activities}

Although of lesser concern to the current paper, it is worth noting that with regard to living labs as spaces where designers and researches find inspiration, (as discussed in section 1.1), various locations are used, or suggested, for carrying out living lab activities in the reviewed papers. These include, use of naturalistic environments such as peoples' personal homes [22]; lab type environments such as mock-up homes in care facilities [9]; community centres (van Geenhuizen [31]); online technological platforms (e.g. [34]), and university spaces. This observation attests that living labs are not so much about the existence of a physical or permanent space, but rather about the creation of an appropriate environment and suitable conditions to facilitate their activities.

\subsection{Geographical regions of the living labs}

The majority of the selected papers reported on European projects or living labs/consortium of living labs based in European countries, with the exception of two papers, one from China [34] and one from Australia [24]. This reflects more than a decade of government support for the living lab approach in European countries (except for the United Kingdom) and highlights that the living lab movement is only just emerging in other parts of the world.

\subsection{Purposes/motivations of the living labs}

The distribution of topics being examined within the living labs as a focus of co-creation with older adults, was relatively 
unsurprising. Notably, information and communication technology were discussed relatively frequently including technologies such as mobile applications and platforms mediated by smart phones, tablets and computers [1, 19, 31, 34]. Equally discussed were 'social innovations', such as strategies to address nutrition in frailty, autonomous mobility, isolation and social communication or integration [2, 22]. Next in frequency of discussion were technologies that related to telehealth or Personal Health Systems including wearable personal alarms, which might also be mediated by ICT [24, 26, 33]. This was equal in number to the occurrence of innovations for dementia care and focus on older adults living with cognitive disorders $[8,9,25]$. Papers suggesting a focus on solutions for assistive living occurred in only one of the papers [23]. Yasuoka et al. [35] discussed a range of topics related to service design, in eight different living lab cases (five of the cases are related to older adults). The cases included topics such as, 'welfare equipment', childcare products for use by grandparents giving childcare, (which was a more unexpected finding), and unspecified healthcare products and services, but note, some of the living labs/projects or proposals focused on more than one topic described here.

It was notable that Wang and Xing [34]; [26] and Yasuoka et al. [35] were theoretical papers- where no practical 'cocreation' took place, but the value of using the living lab approach was described as well as proposed methods. Wang and Xing [34], for example, proposes an alternative method where resources are scarce; [26]) proposes an alternative where other methods are seen as inadequate and Yasuoka et al. [35] provides analysis of eight case examples with a view to understanding the features of living labs that might be applied to service design (five of these case examples are relevant to co-creating with older adults).

\subsection{Actors involved in the development and activities in the living labs}

Although not documented in the results table (Table 2) it is worth noting that most of the papers emphasised, to some degree, the need for collaboration between interdisciplinary teams of actors, for understanding the needs of older adults (except for [34]). The involvement of older adults, or their proxies, (i.e., formal and informal health and social care providers, family members) in the exploration of older adults' needs is also evident in all the papers, although this varied to greater or lesser extents. Overall, the papers suggest that there is effort to co-design/develop technologies and services and there is appreciation of complexities associated with innovating for and with older adults, which requires a collaborative approach (e.g., in some cases professional carers are seen as end-users and exploration of how what they need to help older people is the goal of 'co-creation'). The described actors and partnerships are as follows,
- Transdisciplinary academics (e.g. designers, economists, engineers, healthcare professionals, collaborating with existing associations like business entities and policymakers, [2])

- Human factor specialists, psychologists, physicians, engineers, designers, sociologists, and health economists (the living lab has affiliations with two hospitals and a national centre for older adults living with cognitive disorders, Pino et al. [25].

- van Geenhuizen, [31]; Brankaert and den Ouden [9] Pedell et al. [24]; Kopec et al. [19]; Andersen et al. [1]; Malmborg et al. [22]; Brankaert and den Ouden [8]; Vermueulen et al. [33] and Moutmtzi and Wills [23] reported activities as being led by researchers in collaboration with various stakeholders including industry partners, community co-ordinators, older adults, care professionals and informal caregivers.

\subsection{Described methods in the selected papers}

The methods described in the selected papers are summarised in Table 2. Along with the descriptions presented in 3.2 (geographical regions of the living labs) they should be read in the context of the purposes/motivations (described in 3.3) of the living lab/project or proposed method, that is, according to what the living lab is trying to achieve. For example, in the Pedell et al., [24] paper, it is important for the reader to understand that the goal of the living lab project is to help older adults to communicate their emotions.

\section{Discussion}

The employed methods of this review exemplify the five guiding principles of living labs documented in the wider literature, alluded to earlier in this paper, i.e., continuity; openness; realism; empowerment of users, and spontaneity [6]. The methods used/suggested by Brankaert and den Ouden [9] and [23] for example, advocate cross-border collaboration among stakeholders and this is seen as important to strengthen creativity [6]. The second guiding principle suggests that openness is important in order to gather many perspectives and also to support the process of user-driven innovation. In this regard, all of the reviewed papers, where businesses have a focus on product development, appear to open their research and development processes to their environment so inviting the sharing of ideas. The guiding principle of Realism suggests the need to generate as realistic use situations and behaviours that are as realistic as possible, and the methods described by Brankaert and den Ouden [9] exemplify this principle. The Empowerment of users is demonstrated in the Spiral approach, Kopec, Nielek and Wierzbicki, [19] and 
capitalises on the creative power of user communities [6] by engaging them in innovation processes. The principle of spontaneity is exemplified in this review by the methods used when innovating with older people with cognitive decline $[9,25]$. Ultimately, all of the described methods, according to the ethos of living lab co-creation, aim to understand the needs of older adults, either as an explicit goal (e.g., Pino et al., [25] or this goal is implied by a broader ethos of inclusion. From this perspective two themes stand out from the review, as follows.

\subsection{Willingness to adapt methods is desirable when co-creating with older adults}

Significantly, some of the papers identify confounding factors that may make product development and testing with older adults more challenging than other social groups. For example, there may be complicating factors such as cognitive decline [9, 25]; issues of trust [31] and scarcity of resources [34], limiting the involvement of older adults actively and readily in co-creation. Moreover, it is not always useful to consider the degree to which older adults are or can be active in collaboration/co-creation because situations are not always comparable, [9, 25]. For example, we cannot compare the living lab processes adopted involving people living with cognitive decline with situations where people have no impedance to participation. As an illustration of this, Pino et al. [25] suggest that their older participants, who have cognitive decline, can be said to be 'active' in co-creation in so much as they are involved in idea generation through their reactions to scenarios that are acted out by facilitators. [9]) described methods also appear to be comparable to descriptions of test-bed-like evaluation, on first reading, but the authors emphasise that, on the contrary, the approach they describe is distinct from simply prototype testing approach of gathering after-use feedback to improve the system ([9] p46). Rather, they suggest their methods aimed to reveal latent uses, by exploring how caregivers use the system in practice (with older adults), to allow new insights to be revealed and add to the value proposition of the system (p46). In this sense, the care professionals and older adults can be seen as the beneficiaries of the system and they are influencing the design of the product.

In these more complex situations, the reviewed papers indicate that research methods can be adopted/designed to gather useful feedback using less familiar methods but that these adaptations don't devalue the ethos of co-creation. Wang and Xing [34], and Moutmtzi and Wills [23], also propose methods that might appear to be less favourable to the notion of 'co-creation'. They indicate ICT-mediated living lab processes. For example, Wang and Xing [34] suggest they might construct 'real life' contexts through ICT, stimulate users to express their real needs in real life context, or collect data automatically by computer information systems (ibid, p4632). The authors suggest that such approaches might replace perhaps more resource-laden 'expert mediated' interviews and focus groups, field trials and ethnography that are more conventional approaches in living labs. Although unconventional, those methods might provide a solution to the time and people challenges associated with co-creating with older adults that innovators/service designers face in China, but where solutions to the provision of extensive healthcare services are needed, especially in hard to reach areas. Given that population ageing is an issue of global concern, and if we are to believe in the potential of technologies and in the concept of co-design with older adults as crucial to adoption of innovation and technological solutions, then we need to be open to discuss the value of new user-involvement methods.

Angelini et al. [2] also places high importance on observational methods (i.e., low user involvement) as a means of gaining insights into older adults' habits and behaviours and the problems and needs they encounter, in natural contexts. The described 'ethnographic' approach is comprehensive, (involving, Community Based Participatory Research-CBPR; world café and shadowing techniques) and suggested to be 'ecological' (involving the co-operation of various older age stakeholders and organisations, researchers; designers; businesses; senior associations and institutions and older adults themselves). Furthermore, it "allows for discovering the latent needs of the older adults by following them during their daily activities and listing observations" ([2] p1). Notably, this method is valued in Social Anthropology. From the discussion presented in Angelini et al. [2], it is clear that the approach is utilised and highly valued in this situation also, to elicit important information to assist the design of products and services.

Consequently, the authors of this current review suggest that passive involvement by older adults in cocreation of products and services does not necessarily mean that older adults cannot, or do not, influence the development of these products/services, or that less value should be placed on passive contributions. On the contrary, whether employing passive or more active user involvement roles, many of the methods described by the authors, as discussed above, are designed to gain richer understanding of the needs of older adults to inform better design of products/services.

The discussed approaches to living lab co-creation acknowledges that older adults are not a homogeneous group of people. They may have multiple determinants of health and/or might not be able to express their needs and wants or provide feedback in more conventional ways, [26]. Indeed, as highlighted by Angelini et al. [2] in relation to ICT, "older adult" is not a good enough segmentation for 
the design of ICT based solutions", ([2], p13). Such complexities have bearing on how co-creation might proceed and are compounded by a scarcity of assessment tools and user research methods [2]. Consequently, innovators and living labs in this field, as evidenced here, may need to adopt methods that optimise possibilities to truly understand the needs of the older adults and adapt methods during projects.

\subsection{Living lab approaches exist along a continuum}

Subsequent to the above findings, and as inferred in Angelini et al. $[2,31]$ it might be suggested that living labs use approaches that could be described as existing along a continuum of co-creation, where at one end, 'quasi' complete products are tested/played with by potential users in order to fine tune them, while at the other end of the continuum, potential users actively participate in codesign to highlight their needs from the beginning ([2] p5). Indeed, potential users might go beyond simply being involved by acquiring an ownership mindset, having ownership of the challenges and problem-solving ideas in design processes, as indicated in the characterisations of living labs in Yasuoka et al. [35]. Implicitly, (and explicit in the case of [19]), this latter viewpoint of user involvement presents a rebuke to some living lab methodologies, which proclaim to co-design with older adults but essentially involves end-users as passive participants. With regard to product design and development more specifically, co-creation might be viewed as having different extents to which users' involvement can influence the idea, development and launch processes, by an active and collaborative user having significant influence whilst passive user involvement provides for little, if any, influence on design processes ([7] p44).

Implicit in the literature under review, is the idea that different living lab approaches may have a greater or lesser value, depending on the methodology used (although this is not stated explicitly by any of the authors). Moreover, it might be suggested that the approaches used by living labs may be informed by the different philosophical and theoretical underpinnings that inform the approach used to test or co-creating with older adults.

The findings of this review therefore reflect the observations of Beutel et al. [7] who noted that user involvement has come to be regarded as a fundamental to dimension to cocreation (p1455). Moreover, "manufacturing companies have been increasingly open to approaches that define the product based on what people need" ([28] p5) It is reassuring that with regard to co-creating with older adults, exploring the needs of the older adults is also evident for more altruistic social/user good motivations.

\section{Summary and conclusion}

This paper set out to review the fourteen papers that were selected in a search relating to co-creation in living labs concerned with older adults. It has explored important concepts, evident in the papers, relating to the philosophy of co-creation and how these are enacted in practice in living labs, living lab projects and in proposed methods for co-creation. Examination of the methods of the living labs illustrate that exploring the needs of older adults to enable them to adopt technological and service solutions to everyday challenges is a central concept in living lab research methods and is integral to co-creation. This exploration of needs can be facilitated by an array of different methods associated with co-creation, not exclusive of more traditional research methods such as focus groups, interviews, questionnaires and literature reviews, which are not redundant when the motivation is to understand user needs: they can complement more creative and inclusive methods. Importantly, the methods of co-creation with older adults in this review suggest that co-creation might be viewed as 'legitimate' even when there is low involvement of older adults in the design/development process, however, inclusive methods that involve end-users from the early stages of design (or concept) are regarded as most conducive with needs finding and effective co-creation. Needs finding might be interpreted such that more remote methods to achieve it can be used, evoking a type of continuum of co-creation.

Depending on the project focus, living lab personnel might draw from a repertoire of methods to understand the needs of older adults in relation to technological product design and use and innovative service uptake. Importantly, though there is no indication of methods being fixed in any of the living lab approaches, rather they suggest flexibility, and in some cases iterative steps, in the adopted methods to accommodate the aims of co-creation with older adults. Therefore, having a repertoire of potential methods seems to be the optimal approach to co-creating with older adults and being creative with these is desirable especially in situations where user needs cannot be readily articulated. Businesses innovating in this space may benefit from the comprehensive and thorough approaches to needs finding described in the papers of this review.

\subsection{Limitations of the study}

Clearly there is need for consideration of some important issues relating to the acceptance and use of technological and service solutions among older adults, which are not addressed in this paper. These include, but are not limited to, factors identified in the varying iterations of the Technology Acceptance Model, Davis et al. [12] and debate about the wider societal discourse on 'independent ageing', which might be viewed by some older adults as presenting a, perhaps 
unintended, dehumanising and ageist view of older adults and concern about privacy and security inherent in the features of some of the products being developed.

The authors of this review also acknowledge that it might also have been interesting to include research papers focusing on 'smart cities' in the review since such papers might also have involved utilising living lab methods with older people. Researchers should bear this in mind for any future related review in this area.

\section{Compliance with ethical standards}

Conflict of interest The authors declare that they have no conflict of interest.

Ethical approval This article does not contain any studies with human participants or animals performed by any of the authors.

Informed consent Informed consent was not necessary for this review.

Open Access This article is licensed under a Creative Commons Attribution 4.0 International License, which permits use, sharing, adaptation, distribution and reproduction in any medium or format, as long as you give appropriate credit to the original author(s) and the source, provide a link to the Creative Commons licence, and indicate if changes were made. The images or other third party material in this article are included in the article's Creative Commons licence, unless indicated otherwise in a credit line to the material. If material is not included in the article's Creative Commons licence and your intended use is not permitted by statutory regulation or exceeds the permitted use, you will need to obtain permission directly from the copyright holder. To view a copy of this licence, visit http://creativecommons.org/licenses/by/4.0/.

\section{References}

1. Andersen TO, Kanstrup AM, Yndigegn SL. Three living labs in Denmark: challenges with co-design and implementation of health IT. IN Proceedings from the 16th Scandinavian Conference on Health Informatics 2018, Aalborg, Denmark August 28-29, 2018. Linköping University Electronic Press. 2018;1-6.

2. Angelini L, et al. Senior living lab: an ecological approach to foster social innovation in an ageing society. Future Internet. 2016;8(50): $1-19$.

3. Arksey H, O'Malley L. Scoping studies: towards a methodological framework. Int J Soc Res Methodol. 2005;8(1):19-32.

4. Bannon, L.J. and Ehn, P. Design: design matters in participatory design. Routledge International Handbook of Participatory Design, Simonsen, J. \& Robertson, T., (eds), Routledge (2012), 37-63.

5. Bekker M, Long J. User involvement in the Design of HumanComputer Interactions: some similarities and differences between design approaches. In: McDonald S, Waern Y, Cockton G, editors. People and computers XIV — usability or Else! London: Springer; 2000.

6. Bergvall-Kåreborn, B. and Ståhlbröst, A., (2009), Living lab - an open and citizen-centric approach for Innovation. International Journal of Innovation and Regional Development.

7. Beutel T, Jonas JM, Moeslein KM. Co-creation and user involvement in a living lab: an evaluation of applied methods, 13th
International Conference on Wirtschaftsinformatik, February 12 15, (2017), St. Switzerland: Gallen; 2017.

8. Brankaert, R. and den Ouden, E., (2013), Setting up a living lab for innovation in the dementia care chain, a case study of the PhysiCAL. The XXIV International Society for Professional Innovation Management Conference proceedings - Innovating in Global Markets: Challenges for Sustainable Growth Helsinki, Finland 16-19 June (2013).

9. Brankaert R, den Ouden E. The design-driven living lab: a new approach to exploring solutions to complex societal challenges. Technol Innov Manag Rev. 2017;2017:7 (1).

10. Centre for Ageing Better (2019), Industrial strategy challenge fund healthy ageing challenge framework: at: https://www.ageing-better. org.uk/sites/default/files/2019-02/Healthy-Ageing-ChallengeFramework.pdf, accessed on 3/12/2019.

11. Chesbrough, H. Open innovation: The new imperative for creating and profiting from technology. Boston: Harvard Business School Press. (2003).

12. Davis FD, Bagozzi P, Warshaw PR. User acceptance of computer technology: A comparison of two theoretical models. Manag Sci. 1989;35(8):982-1003.

13. Dutilleul B, Birrer FA, Mensink W. Unpacking European living labs: analysing innovation's social dimensions. Central European Journal of Public Policy. 2010;4(1):60-85.

14. European Commission (2018), The silver economy: executive summary (2018): a study prepared for the European Commission DG communications networks, Content \& Technology by: the Technopolis Group and Oxford Economics.

15. Feurstein K, Hesmer A, Hribernik KA, Thoben KD, Schumacher J. Living labs: a new development Strategy. In European Living Labs - A New Approach for Human Centric Regional Innovation, edited by J. Schumacher and. V P Niitamo Wissenschaftlicher Verlag: Berlin. 2008;1-14.

16. Fischer SH, David D, Crotty BH, Dierks M, Safran C. Acceptance and use of health information technology by community-dwelling elders. International Journal of Medical Informatics. 2014), Sep 1;83(9):624-35.

17. Industrial Strategy: Building a Britain for the Future (2018), at: https://www.gov.uk/government/publications/industrial-strategythe-grand-challenges/industrial-strategy-the-grand-challenges, accessed on 03/12/2019.

18. Khosravi P, Ghapanchi AH. Investigating the effectiveness of technologies applied to assist seniors: A systematic literature review. International Journal of Medical Informatics. 2016;85(1):17-26.

19. Kopec W, Nielek R, Wierzbicki A. Guidelines towards better participation of older adults in software development processes using a new SPIRAL method and participatory approach. International Workshop on Cooperative and Human Aspects of Software Engineering (CHASE) May 27th 2018, Gothenburg, Sweden. (2018). https://ieeexplore.ieee.org/stamp/stamp.jsp?arnumber= 8445536.

20. Lander RE. Design for User Empowerment. Interactions. 2015;2015:25-9.

21. Leminen S, Nyström AG, Westerlund M. A typology of creative consumers in living labs. J Eng Technol Manag. 2015;37:6-20 https://www.sciencedirect.com/science/article/pii/ S0923474815000375.

22. Malmborg L, Binder T, Brandt E. Co-designing senior interaction: inspiration stories for participatory design with health and social care institutions workshop, Proceedings of the $11^{\text {th }}$ Participatory Design Conference 2010, November 29-December 3, (2010). Australia: Sydney; 2010.

23. Moutmtzi, V. and Wills, C., (2009) Utilizing living labs approach for the validation of Services for the Assisting Living of elderly people, (2009), 3rd IEEE International Conference on Digital Ecosystems and Technologies. 
24. Pedell, S., et al., (2016) Methods for supporting older users in communicating their emotions at different phases of a living lab project Technology Innovation Management Review (2017) 7 (2) 7-19.

25. Pino $\mathrm{M}$, et al. Contribution of the living lab approach to the development, assessment and provision of assistive technologies for supporting older adults with cognitive disorders. Studia Informatica Universalis. 2013;11(2):34-62.

26. Pino, M., et al., (2015), Innovative technology-based healthcare and support Services for Older Adults: how and why industrial initiatives convert to the living lab approach. Proceedings of the International Conference on Human Aspects of IT for the Aged Population (2015, Los Angeles California USA. Published by springer international publishing Switzerland (2015), 158-169.

27. Procter R, Greenhalgh T, Wherton J, Sugarhood P, Rouncefield M, Hinder S. The day-to-day co-production of ageing in place. Computer Supported Cooperative Work (CSCW). 2014;23:24567.

28. Sanders, E. and Stappers P., (2008), Co-creation and the new landscapes of design. Co-design 4, 1 (2008), 5-18.

29. Schuurman, D., Mahr, D., De Marez, L., Ballon, P., (2013), A fourfold typology of living labs: an empirical investigation amongst the ENoLL community. In Proceedings of the 2013 International Conference on Engineering, Technology and Innovation (ICE) \& IEEE International Technology Management Conference, The Hague, The Netherlands, 24-26 June (2013), 1-11.
30. Shaw et al. Studying scale-up and spread as social practice: theoretical introduction and empirical case study. J Med Internet Res. 2017; Available from: https://www.ncbi.nlm.nih.gov/pmc/articles/ PMC5522581/.

31. van Geenhuizen, M., (2014), Living labs: concepts and critical factors, with case studies in health care, IN Gibson, D. and Slovak, J. (2015) Building Sustainable R\&D Centers in Emerging Technology Regions Masaryk University.

32. Venkatesh V, Morris MG, Davis GB, Davis FD. User acceptance of information technology: toward a unified view. MIS Q. 2003;27(3): 425.

33. Vermueulen, et al. eLabel: technology-supported living labs in primary care. The Seventh International Conference on eHealth, Telemedicine, and Social Medicine, Volume: IARIA; 2015:179182.

34. Wang AF, Xing XZ. Design intelligent service for elderly people using living lab approach. Appl Mech Mater. 2014;543-547:4630 $3 \mathrm{https}: / /$ doi.org/10.4028/www.scientific.net/amm.543-547.4630.

35. Yasuoka, M. et al., (2018), Living labs as a methodology for service design- an analysis based on cases and discussions from a systems approach viewpoint. Proceedings of the DESIGN 2018: 15th International Design Conference, May 21-24, 2018, Dubrovnik, Croatia.

Publisher's note Springer Nature remains neutral with regard to jurisdictional claims in published maps and institutional affiliations. 